\title{
Anesthesia Student Survival Guide: A Case-Based Approach, 2nd Edition
}

\author{
Jesse M Ehrenfeld, Richard D Urman, Scott Segal (Editors). Springer International \\ Publishing Switzerland, 2016; ISBN: 978-3-319-11082-0
}

Mullein D. Thorleifson, MD

Received: 7 July 2016/ Accepted: 18 July 2016/Published online: 28 July 2016

(C) Canadian Anesthesiologists' Society 2016

This updated comprehensive anesthesia field guide begins, as in the first edition, with 32 case studies, each with a series of questions that guide the thought process and anesthetic planning for the case. Each case corresponds to a particular chapter, discussing a core topic pertinent to anesthesia. This is a creative way to encourage focussed critical thinking and engage the learner in the topic. The case studies even extend to the history of anesthesia, making the origins of the specialty personal and absorbing. Answers to the questions posed about the cases are answered at the end of the chapters, with suggestions for further reading.

Rousing support for the specialty of anesthesia opens this easily understandable handbook. From the outset, it offers guidance to medical students rotating through the specialty. Chapter 1 is entitled, How to Be a "Star" Student, Career Options, and the "Match", which captures the reader's attention. The career options and match are addressed through an American training lens, however. Although the overall advice and lessons will be useful for trainees in various systems, the real pearls about navigating the system, which may be enlightening for US learners, are probably less useful to non-US trainees.

Topics are covered in thorough detail, which results in a book that does not fit comfortably in a pocket. The main points are in boldface type (as though the reader has already insightfully highlighted the key points), and the tone of the text is friendly and engaging, making this guide a readable resource for the operating room.

M. D. Thorleifson, MD ( $ه)$

Department of Anesthesia and Perioperative Medicine,

University of Manitoba, Winnipeg, MB, Canada

e-mail: umthorle@myumanitoba.ca
The book contains many pearls, such as features of an ideal anesthetic agent in Chapter 4 and characteristics of the various modes of ventilation in Chapter 10. The scope of the book is sufficiently broad that perusal of the index in the heat of a clinical moment is apt to be fruitful. Learners will appreciate the ability to look up everything from features of the anesthetic machine to pharmacology of various anesthetic drugs to the basics of pain management. Physiology is succinctly addressed in relation to surgical procedures throughout the text.

Concepts are quickly and clearly explained in the numerous tables and figures throughout the text. At times, however, the tables are just a random checklist without clear organization (e.g., the list of physiologic changes of pregnancy in Chapter 20).

Preoperative assessment and airway evaluation discussed in Chapters 8 and 9 comprise perhaps the most high-yield sections for medical students as this extremely important component of anesthesia provision is often delegated to junior trainees. The updated information included in this second edition is a valuable addition.

Ethics and professionalism are topics that are timely, with their importance being increasingly recognized. Emphasising these topics in texts geared toward medical professionals at the beginning of their careers is critical and commendable. Chapters 30 to 32 address them in a sensitive and encouraging way.

The inclusion of malignant hyperthermia management and the reference to the American Society of Anesthesiologists difficult airway algorithm is helpful. Unfortunately, however, the airway algorithm itself was not included. Perhaps guidelines to be included in future editions could include a summary of the American Society of Regional Anesthesia/European Society of Regional 
Anesthesia and Pain Therapy guidelines regarding anticoagulation and regional anesthesia, or the American College of Cardiology/American Heart Association guidelines for patients with cardiac disease undergoing non-cardiac surgery.

References are largely not provided, with the exception of images from named sources. The information provided, however, is consistent with standard anesthesia texts, and many of the images are sourced from these books.

This text is useful, comprehensive, and enjoyable to read. It is ideal for medical students and junior residents as it can help them organize their days on anesthesia rotations and understand essential background information. Elective students and residents may find it particularly helpful to use the text to generate an anesthetic plan and predict intraoperative events, especially when these learners have never participated in the case at hand. Descriptions of procedures are adequate for those at the learning stage, who will have a more senior anesthetist present. The descriptions provide excellent background details to inform further learning. The suggested pre-reading and postreading literature would be useful for junior residents to review as well. For senior residents, the tables in the text and simple summaries may provide some fodder for studying short-answer examination questions and a reference for core concepts. The text could be a handy pocket guide for staff anesthesiologists, offering some level-appropriate suggestions for teaching topics around particular cases in the operating room. All of these various uses would make it an ideal book for a departmental library.

Conflicts of interest None declared.

Editorial responsibility This submission was handled by Dr. Hilary P. Grocott, Editor-in-Chief, Canadian Journal of Anesthesia. 